\title{
Article
}

\section{Phenotypic responses in caenorhabditis elegans following Chronic low-level exposures to inorganic and organic Compounds}

Mugova, Fidelos, Read, Daniel. S, Riding, Matthew. J, Martin, Francis L, Tyne, William, Svendsen, Claus and Spurgeon, David

Available at http://clok.uclan.ac.uk/20565/

Mugova, Fidelos, Read, Daniel. S, Riding, Matthew. J, Martin, Francis L ORCID: 0000-0001-8562-4944, Tyne, William, Svendsen, Claus and Spurgeon, David (2018) Phenotypic responses in caenorhabditis elegans following Chronic lowlevel exposures to inorganic and organic Compounds. Environmental Toxicology, 37 (3). pp. 920-930. ISSN 1520-4081

It is advisable to refer to the publisher's version if you intend to cite from the work. http://dx.doi.org/10.1002/etc.4026

For more information about UCLan's research in this area go to http://www.uclan.ac.uk/researchgroups/ and search for <name of research Group>.

For information about Research generally at UCLan please go to http://www.uclan.ac.uk/research/

All outputs in CLoK are protected by Intellectual Property Rights law, including Copyright law. Copyright, IPR and Moral Rights for the works on this site are retained by the individual authors and/or other copyright owners. Terms and conditions for use of this material are defined in the policies page. 


\section{Environmental Toxicology and Chemistry}

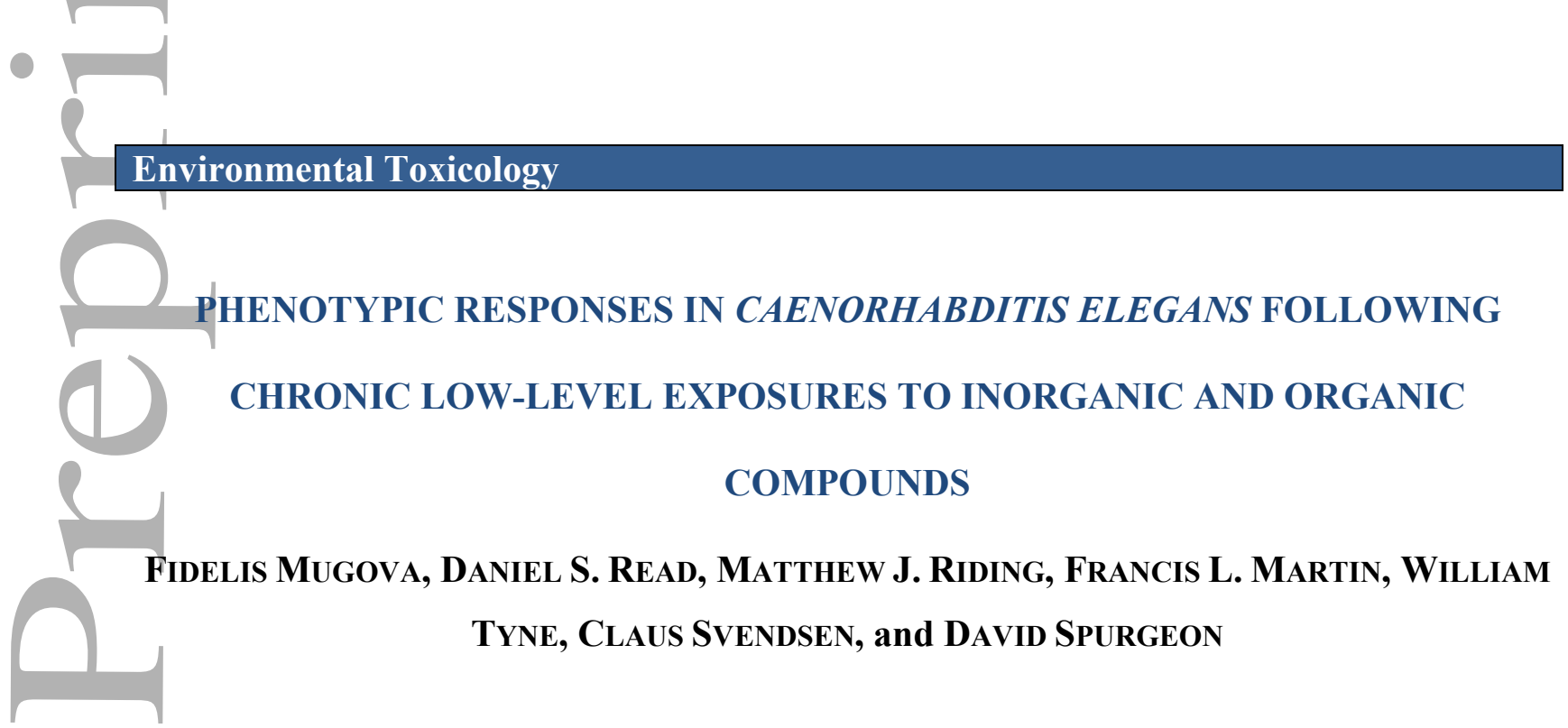

Environ Toxicol Chem., Accepted Article • DOI: 10.1002/etc.4026

\section{$(1)$

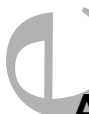 \\ Accepted Article}

"Accepted Articles" are peer-reviewed, accepted manuscripts that have not been edited, formatted, or in any way altered by the authors since acceptance. They are citable by the Digital Object Identifier (DOI). After the manuscript is edited and formatted, it will be removed from the "Accepted Articles" Web site and published as an Early View article. Note that editing may introduce changes to the manuscript text and/or graphics which could affect content, and all legal disclaimers and ethical guidelines that apply to the journal pertain. SETAC cannot be held responsible for errors or consequences arising from the use of information contained in these manuscripts.

This article is protected by copyright. All rights reserved 
Environmental Toxicology

F. Mugova et al.

Raman phenotyping of chemical exposure in nematodes

PHENOTYPIC RESPONSES IN CAENORHABDITIS ELEGANS FOLLOWING CHRONIC LOW-LEVEL EXPOSURES TO INORGANIC AND ORGANIC

\section{COMPOUNDS}

Fidelis Mugova, ${ }^{1,2}$ Daniel S. Read, ${ }^{2}$ Matthew J. Riding, ${ }^{1}$ Francis L. Martin, ${ }^{1,3}$ William Tyne, ${ }^{2}$ Claus Svendsen, ${ }^{2}$ and David SpurgeON ${ }^{2, *}$

${ }^{1}$ Centre for Biophotonics, Lancaster University, Bailrigg, Lancaster, UK ${ }^{2}$ Centre for Ecology \& Hydrology, Maclean Building, Benson Lane, Crowmarsh Gifford, Wallingford, UK

( ${ }^{3}$ School of Pharmacy and Biomedical Sciences, Maudland Building, University of Central

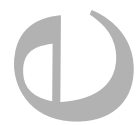
Lancashire, Preston, UK

1

* Address correspondence to dasp@ceh.ac.uk

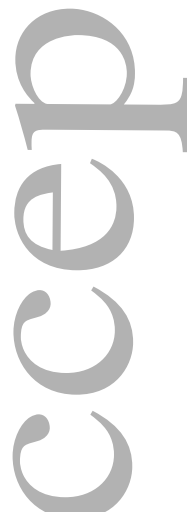

This article contains online-only Supplemental Data

This article is protected by copyright. All rights reserved

Submitted 4 January 2017; Returned for Revision 26 March 2017; Accepted 31 October 2017

This article is protected by copyright. All rights reserved 
Abstract: Responses of organisms to sub-lethal exposure of environmental stressors can be difficult to detect. We investigated phenotypic changes in the tissue of Caenorhabditis elegans via

Raman spectroscopy, as well as survival and reproductive output when exposed to chronic low dose of exposure metals (copper, zinc or silver), an herbicide (diuron) and a pesticide (imidacloprid). Raman spectroscopy measures changes in phenotype by providing information about the molecular composition and relative abundance of biomolecules. Multivariate analysis was used to evaluate the significance of treatment phenotype segregation plots compared to controls. Dose-dependent responses were observed for copper, zinc, silver and diuron while imidacloprid exposure resulted in a small response over the tested concentrations. Concentrationdependent shifts in nematode biomolecular phenotype were observed for copper. Despite having a dose-dependent reproductive response, silver, diuron and imidaclorprid had inconsistent biological phenotype patterns. In contrast, there was a clear stepwise change between low concentrations $(0.00625-0.5 \mathrm{mg} / \mathrm{L})$ and higher concentration $(1-2 \mathrm{mg} / \mathrm{L})$ of ionic zinc. The findings demonstrate that measuring phenotypic responses via Raman spectroscopy can provide I an insight into the biomolecular mechanisms of toxicity. Despite the lack of consistency between survival and Raman-measured phenotypic changes, the results supports the effectiveness of Raman spectroscopy and multivariate analysis to detect sub-lethal responses of chemicals on whole organisms and to identify toxic effect thresholds. This article is protected by copyright. All rights reserved

Keywords: Multivariate, Toxic, Ecotoxicology, Biospectroscopy, Raman, Phenotype

This article is protected by copyright. All rights reserved 


\section{INTRODUCTION}

The complex interaction between genotype and environment in organisms exposed to

stress is manifested through altered biomolecule composition, physiological activity, behaviour or life-cycle endpoints [1-3]. Cellular phenotypic responses such as changes in gene expression, metabolite or protein production have the potential to be more sensitive indicators of stress than conventional organism-level measurements such as survival, growth or fecundity. In addition, due to the ability to identify specific genetic or biomolecular changes, measurements of the cellular phenotype have the potential to reveal the nature of the underlying mechanism of toxicity [4]. Hence, the studying of biochemical changes in response to chemical exposure can provide information to support the risk assessment of chemicals and emerging nanomaterials [5]. A range of techniques are capable of measuring the cellular or organismal phenotype.

Available methods include biochemical assays, transcriptomics, proteomics and biomolecular fingerprinting approaches. One such fingerprinting technique is Raman spectroscopy. Raman is a rapid, label-free vibrational spectroscopy that can be used to characterise and discriminate, an I organisms' response to biotic and abiotic factors [6-12], including chemical exposure [8,13].

Within Raman spectroscopy, molecules are identified based on their inelastic scattering of light

by the vibrational modes of chemical bonds, facilitating phenotypic screening of whole biological samples $[7,14]$. Biomolecules such as nucleic acids, proteins, carbohydrates and lipids all have unique Raman vibrational modes which provide information about the bonding, structure and molecular symmetry [15]. The analysis can be applied to in vivo conditions without fixatives, stains or markers $[16,17]$. In confocal systems, this information can be obtained with micrometre-level resolutions which allows both qualitative and quantitative analysis [18]. Variations in Raman-derived biological phenotypes can reveal biochemical changes in response 
to stimuli [19] by providing an insight into the overall chemical of a biological sample in a nondestructive manner.

To investigate the value of Raman spectroscopy as a biochemical fingerprinting tool in ecotoxicological studies, biomolecular phenotypes were investigated in the nematode, Caenorhabditis elegans, a commonly used model species for mechanistic toxicity studies, exposed to chronic low-levels of inorganic (copper, zinc or silver) and organic (diuron or imidacloprid) chemicals. Parallel studies to effects on reproduction were also conducted to provide life-history comparisons to the observed biochemical changes. The compounds selected for study were chosen due to their prevalence and known persistence as environmental contaminants [20]. Further, the selected chemicals cover a range of different modes of action including non-essential and essential metals and pesticides with likely modes of action linked to putative electron transport disruption and effects on nerve function. Our aim was ultimately to establish the nature of the common mode of action and specific shift in metabolic resources that are linked to reproductive toxic effects in exposed nematodes and to compare the sensitivity of I Raman phenotyping with that of a classic life-cycle endpoint as measures of toxicological stress.

\section{MATERIALS AND METHODS}

\section{Caenorhabditis elegans stock culture}

Wild-type Bristol N2 nematodes obtained from the Caenorhabditis Genetics Centre (University of Minnesota, MN, USA) were grown in $90 \mathrm{~mm}$ petri dishes on nematode growth medium [21]. Worms were fed with Escherichia coli strain OP50 grown as a bacterial lawn as a food source during culturing and exposure experiments. Stock cultures were kept in the dark and incubated at $18^{\circ} \mathrm{C}$. Nematodes were transferred to new plates on a weekly basis to maintain a healthy, synchronised population for use in all bioassays. 
Media for chemical exposure

The choice of exposure media was based on a previous study [22] which developed and

optimised a synthetic soil pore water (SSPW) for use in toxicity tests. This liquid media provides a closer approximation to natural soil solution conditions than alternative media. Notably the SSPW has a lower ionic strength than other test solutions such as K-media and M9 buffer which is more representative of typical soil solution conditions for a typical circum-neutral agricultural mineral soil [22]. This means that SSPW provides a more realistic chemical bioavailability within the test system. The media contains varying concentrations of essential ionic compounds needed for growth by $C$. elegans [22]. Two $1 \mathrm{~L}$ batches were prepared and the solutions bubbled with air over night to equilibrate the dissolved $\mathrm{CO}_{2}$ with the atmosphere, stabilising $\mathrm{pH}$ at $\sim 8.2$ prior to the start of exposure.

Stock solutions for chemical exposure

Analytical grades of copper (II) chloride [ $\left.\mathrm{CuCl}_{2}\right]$, copper (II) sulphate [CuSO 4$]$, imidacloprid $\left[\mathrm{C}_{9} \mathrm{H}_{10} \mathrm{ClN}_{5} \mathrm{O}_{2}\right]$, zinc chloride $\left[\mathrm{ZnCl}_{2}\right]$, silver nitrate $\left[\mathrm{AgNO}_{3}\right]$ and diuron $\| \quad\left[\mathrm{O}_{9} \mathrm{H}_{10} \mathrm{Cl}_{2} \mathrm{~N}_{2} \mathrm{O}\right]$ (all purchased from Sigma-Aldrich, UK) were used for all experiments. Stock solutions were made by dissolving the following masses in $10 \mathrm{~mL} \mathrm{SSPW:} \mathrm{copper} \mathrm{chloride} \mathrm{(2.54}$ $\mathrm{mg})$; copper sulphate $(3.01 \mathrm{mg})$; zinc chloride $(2.57 \mathrm{mg})$; silver chloride $(2 \mathrm{mg})$; and imidacloprid (30 mg). All inorganic compounds and the neonicotinoid imidacloprid were highly soluble in SSPW alone. The highest concentrations of the chemical in each were prepared as a stock solution, with subsequent treatments made based on a dilution of this stock. Organic compounds with a low solubility in SSPW, in this case diuron, were prepared as initial stock solutions in acetone that were then used for dosing the main test treatments.

Design of reproduction toxicity tests

This article is protected by copyright. All rights reserved 
Concentration response relationships for each of the chemical were established through a

set of toxicity test to measure effects on reproduction. The design of these studies used

previously established $\mathrm{EC}_{20}$ values for imidaclorprid [23]; silver [24], diuron [22]; copper [25]

and zinc (W. Tyne unpublished data) to aid selection of concentrations for the exposures that

would be expected to cause effects of reproduction ranging from no effect at lower concentration

to a substantive knock-down (intended $>50 \%$ ) at the highest tested concentrations. The final

ranges $(\mathrm{mg} / \mathrm{L})$ used for these exposures were as follows: copper $(0.01875,0.0375,0.075,0.15$,

$0.3,0.6)$; zinc $(0.0625,0.125,0.25,0.5,1,2)$; silver $(0.0078,0.015,0.031,0.062,0.125,0.25)$;

diuron $(1.125,2.25,4.5,9,18,36)$; and, imidacloprid $(30,15,30,60,120,240,480)$.

The toxicity tests for each chemical were conducted in SSPW to establish the

concentration response relationship for the effect of each chemical on nematode reproduction.

The bioassays comprised short-term (72-hour) toxicity tests, each measured the range of

chemical effects on C. elegans adult survival and reproduction. All exposures were conducted in

SSPW without added fulvic acid as described by Tyne et al. (2013). The SSPW was seeded with

IE. coli OP50 at a concentration of 500 Formazin Attenuation Units (FAU) as a food source, this

level being sufficient to provide sufficient food even if bacterial growth is limited by the

chemical. As a result we can be confident the affects seen were associated with the effects of the

chemical on the exposed nematode and not related to limitation of food supply. Each test was run in six well plates using a $2 \mathrm{~mL}$ exposure volume.

The tests for the inorganic compounds and imidacloprid used six concentrations and a

media only control, while that for diuron used a standard control treatment and an additional

carrier control to validate that there was no effect of the acetone used for chemical dosing on

nematode reproduction. All exposure treatment used were prepared by dilution of the initial

This article is protected by copyright. All rights reserved 
stock solutions. Six replicates were used for each treatment. Each replicate comprised three age synchronized adult $\mathrm{N} 2$ strain $C$. elegans maintained in appropriately dosed media contained within the individual well of a multi-well plate. After the initial addition of the worms to each well, all plates were incubated in constant dark at $18^{\circ} \mathrm{C}$ for 72 hours. At the end of this exposure period, $0.75 \mathrm{~mL}$ of $1 \%$ Bengal red was added to each well to stain the juveniles and eggs and the plates heated to $55^{\circ} \mathrm{C}$ for 30 minutes to kill all adult and juvenile worms. Numbers of adults and progeny were then counted optically for replicate wells.

Concentrations used for the toxicity test were also used for large volume exposure to generate a sample of sufficient biomass for use for Raman spectroscopy analysis. Matching of the test concentrations with the available concentration response data were used to provide information on the scale of expected effect to ensure that the phenotypic effects observed by Raman spectroscopy could be correctly interpreted. These exposures were also conducted in SSPW. Each exposures used a larger batch of nematodes to provide sufficient individuals for sampling. The same protocols was used in respect of test duration and test conditions as for the reproduction toxicity tests. Samples were prepared following exposure to replicate treatments for each chemical and also a matching SSPW only or solvent control.

Freeze-drying samples

Nematode samples were isolated from the exposure solutions by centrifugation in $2 \mathrm{~mL}$ centrifuge tubes and washed in deionised water. The pelleted samples were then freeze dried for 24 hours. Freeze drying has been shown to result in a rapid and consistent maintenance of sample biochemical variation and integrity [26][. The freeze dried nematode samples, containing approximately $100-200$ nematodes per sample, were stored at $-20^{\circ} \mathrm{C}$ prior to Raman spectroscopy.

This article is protected by copyright. All rights reserved 
Raman spectroscopy

A Raman microspectrometer (Horiba Scientific, UK) equipped with a 600 -grooves/mm

grating and a slit width of $100 \mu \mathrm{m}$. A $532 \mathrm{~nm} \mathrm{Nd:YAG} \mathrm{laser} \mathrm{focussed} \mathrm{onto} \mathrm{the} \mathrm{sample} \mathrm{through} \mathrm{a}$ $\times 100,0.9-N A$ Olympus objective. Spectra were acquired from the 300 to $1800 \mathrm{~cm}^{-1}$ wavenumber range with two 30 -second exposures. Subsequent spectra collected by moving the laser in increments of $2 \mu \mathrm{m}$ over an area $10-12 \mu \mathrm{m}$ to create an averaged spectra covering 5 points across the powdered nematode sample. A neutral density filter was used to reduce the laser power by $10 \%$ to $50 \%$ for chemical exposure studies depending on the exposure test, in response to signal strength and levels of fluorescence. Raman spectra were collected by moving the laser in increments of $2 \mu \mathrm{m}$ over an area $20 \times 20 \mu \mathrm{m}$ to create averaged spectra covering 10 points across the freeze dried pellet.

\section{Data analysis}

The data on offspring production from the reproduction tests were analysed for differences between treatments using one-way ANOVA level. Prior to being analysed, data sets I were checked for homogeneity of variance and residuals checked to ensure that the data showed normality and independence. Where significant differences were found $(p<0.05)$, Tukey's test for multiple comparisons of means was used to determine between which treatments differences occurred. This allowed the lowest exposure concentration for each chemicals that resulted in rates of reproduction significantly lower than controls to be identified. This sensitivity for the reproduction test could then be later compared to the results of the Raman analysis to assess comparative sensitivity between the two approaches. In four of the five chemicals tested, the highest exposure concentration did not reduce reproduction to a value less than $50 \%$ of control values. For these chemical reliable $\mathrm{EC}_{50}$ values for effects on reproduction could not be 
calculated. A reduction of greater than 50\% was found for copper in the highest exposure level. For this metal, a reproductive $\mathrm{EC}_{50}$ could be calculated using a three parameter logistic model fitted using the drc package in the R software environment.

The spectra obtained by Raman analysis were initially concatenated to the $400-1800 \mathrm{~cm}^{-}$ ${ }^{1}$ range and baseline corrected, normalised and zeroed using LabSpec 6 software. Raw data was imported into Matlab R2011a (MathWorks, USA) and analysed using IRootLab algorithm for computational biology and vibrational microspectroscopy (http://trevisanj.github.io/irootlab/) within MATLAB $[27,28]$. Principal component analysis plus linear discriminant analysis (PCALDA) is a cascading application that applies LDA to the resultant PCA factors and the quality of information produced is dependent on the amount of PCs employed [7]. PCA looks for the most significant trends in feature classification while LDA looks for significant trends in data classification [29]. LDA offers more discrimination as it maximises in-between class variance and within class variance [30]. After transformation to a different space the shape and location of the original data changes in PCA while LDA does not change location but provides class I separation. The first PC explains the largest possible proportion of the variance in the data matrix while further PCs explain the largest possible proportion of the residual variance in the data matrix that is not explained by the higher order PCs [12]. The use of PCA-LDA computational approach converts each Raman spectrum into a single point from which nearness or segregation indicates spectral phenotypic similarity or differences between treatment-induced and control nematodes. The six most significantly increased peak heights were obtained from PCA-LDA loadings plot (Table 2). A PCA-LDA loadings plot averages the data for each treatment to produce the most significant wavenumbers attributed to induced spectral phenotypes.

This article is protected by copyright. All rights reserved 


\section{RESULTS AND DISCUSSION}

There was significant effect of copper on offspring production $(\mathrm{F}=10.4, p<0.001)$. Post-

hoc comparison using Tukey's test indicated that reproduction over the exposure was significantly lower $(p<0.05)$ at the two highest copper concentrations tested of 0.6 and $1.2 \mathrm{mg} / \mathrm{L}$ compared to the controls (Fig. 1A). Based on this response, an $\mathrm{EC}_{50}$ of 0.465 (95\% CIs 0-0.966) $\mathrm{mg} / \mathrm{L}$ for the effects of copper and C. elegans reproduction was estimated.

The Raman spectroscopy analysis for copper (II) chloride exposure resulted in a concentration-dependent response in the nematode phenotype, as illustrated within a onedimensional PCA-LDA scatter plot (Figure 2A). This plot (and those for the other chemicals) shows the control biochemical fingerprint, as well as those obtained from the exposed nematodes. The highest concentrations of copper used for the population exposure elicited a phenotypic response that differed from that of the control at exposure concentrations as low as $0.0375 \mathrm{mg} / \mathrm{L}$. The results demonstrate the capacity of Raman spectroscopy to detect concentration-dependent phenotypic effects at concentrations up to 20 times lower than those | eliciting a significant effect on reproduction. Raman analysis, thus, is able to provide a sensitive assessment of biochemical perturbation at low exposure concentrations.

The biochemical changes induced by the relatively low copper exposure concentrations may be related to key aspects of the known mechanisms of action of copper for eukaryotic organisms. Copper is an essential cellular component in many enzymes involved in respiration, iron transport and oxidative stress protection processes [31]. Excess copper can initiate the production of highly reactive oxygen species (ROS) such as hydroxyl radicals, superoxide anion, nitric oxide and hydrogen peroxide which could react with functional groups on biological molecules [32]. It has been proposed that copper exposure may result in stunted growth in 
embryos and adult nematodes both as a result of such oxidative stress induced DNA damage, apoptosis and cell membrane effects [31]. Excess ROS has been shown to interact with a wide range of biomolecules [33], including the inactivation and denaturation of proteins [34] as well as damage to nucleic acids [35] and lipids [36] Furthermore, copper has been shown to inhibit growth rate [37] as well as movement and feeding in a concentration-dependent manner [38] in C. elegans.

A vector plot to identify the possible biochemical changes indicated spectral shifts associated with copper exposure (Figure 2B). This analysis identified that Copper (II) chloride induced significantly higher peaks from carbohydrates (carbon-oxygen-carbon (COC) glycosidic linkage at $1051 \mathrm{~cm}^{-1}$ ) while reducing the amino acid phenylalanine (ring vibration peak at 991 $\mathrm{cm}^{-1}$ ) $[8,12]$. In general, bonds associated with proteins (amide I at $1663 \mathrm{~cm}^{-1}$ ), protein and lipids $\left(1462 \mathrm{~cm}^{-1}\right)$ and lipids $\left(1131 \mathrm{~cm}^{-1}\right)$ were elevated while carbon-hydrogen $\left(\mathrm{CH}_{2}\right)$ deformations $\left(1293 \mathrm{~cm}^{-1}\right)$ and lipids (amide III random stretching at $1223 \mathrm{~cm}^{-1}$ ) decreased. While difficult to fully establish a mode of action for copper, the observed biochemical changes indicate changes I in major energy resources (carbohydrates and lipids) indicative of an effect on metabolism; reduced feeding, ROS induced injury or mitochondrial toxicity being possible causes. A peak $1651 \mathrm{~cm}^{-1}$ (here assigned to $\mathrm{C}=\mathrm{C}$ stretching mode in lipids) has previously been associated with oxidative stress in the yeast (Pichia pastoris). There is a known relationship between changes in species energy budget and effects of major life-cycle traits [39], with previous work linking changes in major metabolic pathways to phenotypic effects in nematodes exposed to chemicals with a range of mechanisms of action [40]. Offspring production was significantly affected $(\mathrm{F}=6.04, p<0.001)$ by zinc exposure. Post-hoc analysis indicated that reproduction was significantly lower $(p<0.05)$ in the three 
highest tested concentrations of 1,2 and $4 \mathrm{mg} / \mathrm{L}$ compared to both controls and the lowest tested concentrations of $0.0625 \mathrm{mg} / \mathrm{L}$ (Fig 1B). The overall pattern of effect indicates that while the top

three concentration each resulted in significantly lower reproduction, the magnitude of the effect was not concentration dependent between these three treatments (each resulted in reproduction being reduced by between 49 - $58 \%$ compared to controls. The precise cause of this response pattern are not immediately apparent, although concentration dependent speciation changes may be a possible cause. Because of this levelling of effect at the highest tested concentrations, a logistic model that described the data well could not be fitted although based on results it would be anticipated that the $\mathrm{EC}_{50}$ for zinc could be in the $2-8 \mathrm{mg} / \mathrm{L}$ range.

Zinc plays a critical role in cellular growth, metabolism and differentiation; many enzymes are zinc metalloproteinases, and in addition zinc acts as an antioxidant agent $[41,42]$.

Furthermore, zinc is essential for gene transcription, and deficiency results in several biological problems such as retarded growth and reduced mobility [42]. However, C. elegans has a system that promotes homeostasis in the organism and stepping beyond the capacity of this mechanism | could well be the cause of the sudden shift in phenotype [43]. Despite the systems to maintain zinc homeostasis, changes in metabolic phenotype were found. The phenotypic changes found at the higher zinc exposure concentration suggests that the homeostatic capacity is exceeded and that nematodes are undergoing metabolic stress. The result is that zinc exposure ultimately compromises biological function, cellular integrity and life history characteristics [42-44]. Raman spectroscopy initially showed no shift in biochemical profile at lower zinc concentration $(0.0625 \mathrm{mg} / \mathrm{L}$ to $0.5 \mathrm{mg} / \mathrm{L})$. However, exposure to 1 and $2 \mathrm{mg} / \mathrm{L}$ zinc invoked a significant change in measured phenotype (Figure 3A). In nematodes exposed at these concentrations, higher peaks for polysaccharides (carbonyl group $(\mathrm{C}=\mathrm{O})$ vibrations at $1046 \mathrm{~cm}^{-1}$ ) and significant 
decreases in proteins (nitrogen-hydrogen $(\mathrm{NH})$ stretch in amide II peptide bonds at 1481 and $1237 \mathrm{~cm}^{-1}$ ) were found compared to controls and lower tested concentrations (Figure 3B).

Comparing the sensitivity of changes in reproduction to that of Raman fingerprinting indicates that effects can be detected using both approaches at the same test concentrations, with the thresholds for observed effects occurring in the $1 \mathrm{mg} / \mathrm{L}$. Hence for zinc, while providing additional information on the nature of biochemical changes, the use of Raman spectroscopy does not provide any increase in sensitivity to detect adverse effects when compared to traditional reproduction effect assessment.

There was a significant effect $(\mathrm{F}=3.68, p<0.01)$ of silver on $C$. elegans offspring production. Within the clear concentration-dependent response, reproduction was significantly reduced $(p<0.05)$ at the highest tested concentration of $0.25 \mathrm{mg} / \mathrm{L}$ compared to controls (Fig.

1C). Observation of an effect of silver exposure in the low $\mathrm{mg} / \mathrm{L}$ range is consistent with the results of previous toxicity studies [45]. In a previous study, also conducted with C. elegans in the same SSPW as used in this study, a reproductive $\mathrm{EC}_{50}$ for ionic silver was established at 0.28 I $\mathrm{mg} / \mathrm{L}[22]$. In the current study, exposure to this concentration elicited only an average $25 \%$ reduction in reproduction. This lower level effect at the previous $\mathrm{EC}_{50}$, indicates slightly lower sensitivity in this test compared to previous results. Starting age of the nematodes used for testing and slight difference in food quality could be possible causes for this moderate scale variation in sensitivity between this study and the previous published work.

The Raman phenotypes of nematodes exposed to silver show no consistent pattern in the segregation of the score plots and no obvious dose-response indicating a similar spectral profile between control and exposed treatment (Figure 4A). This suggests that Raman phenotyping may provide a less sensitive initial indication of toxicological effect than reproductive measurement. 
This is perhaps surprising, since silver is well known to be toxic to many organisms [45]. Apart from a consistent decrease in proteins (amino group $\left(\mathrm{NH}_{2}\right)$ deformations in amide II peptide bonds at $1581 \mathrm{~cm}^{-1}$ ) there was a high degree of variability in the phenotype at each concentration (Figure 4B). Silver exposure can cause multi-biological defects in organisms such as impaired ion regulation due to inhibition of $\mathrm{Na}^{+}, \mathrm{K}^{+}$-ATPase, impaired nervous system (hippocampus development) and reduced egg production and viability in aquatic animals [45]. Increased concentrations of silver which cause significant multi-biological defects which are transferrable to progeny [45] which could explain the inconsistency in Raman phenotype observed. However, while these mechanisms of action may be relevant to exposure with $C$. elegans, the results from the Raman phenotypic suggest that such effects do not result in major changes in organism biochemistry that can be detected using this analysis method.

The exposures to diuron used acetone as a carrier to enable dissolution of the chemicals in the artificial soil pore water. We tested for the effects of acetone only exposure on C. elegans Raman-derived phenotype. The PCA-LDA one-dimensional LD1 scatter plots showed a high | degree of overlap between acetone carrier and control nematodes, indeed the spectral profiles almost completely overlap between the treatments (Figure 5A). Therefore, we concluded from this study, that acetone exposure has no significant effect on Raman phenotype. However, even though there is no obvious phenotypic effect of carrier exposure on nematodes, all treatment comparisons were made to the solvent control to avoid the possibility that there is any solvent contribution in the measured phenotype under exposure to diuron.

The exposure with diuron had a significant effect $(\mathrm{F}=11.64, p<0.001)$ on nematode reproduction. Exposure to diuron at a concentration of $9 \mathrm{mg} / \mathrm{L}$ and higher produced significantly fewer juveniles $(p<0.05)$ when compared to level of production found in the control treatment 
(Fig. 1D). A reliable three parameter logistic model could not be fitted to the data. However, the

fact that reproduction was reduced by $52 \%$ at the highest tested concentrations of $36 \mathrm{mg} / \mathrm{L}$,

suggests that the $\mathrm{EC}_{50}$ would be close to this highest tested concentration.

The Raman phenotype for diuron exposure showed a shift in the means of all exposed

nematodes from the control phenotype, regardless of the dose (Figure 6A). However, within this

phenotypic change, a more detailed concentration related phenotypic structure was not observed

across the lower exposure concentrations. Significant further difference was only seen when nematodes were exposed to the highest test concentration of $36 \mathrm{mg} / \mathrm{L}$. This pattern of effect, points to an all or nothing effect of diuron exposure on the Raman phenotype at lower

concentration exposure, with a further threshold passed as concentrations near the reproduction

$\mathrm{EC}_{50}$ are reached. However, the fact that effects on Raman phenotype were observed at 1.125

$\mathrm{mg} / \mathrm{L}$, a concentration 8 times lower than those causing a significant effect on reproduction.

All treatments consistently increased vibrations assigned to some protein peaks (carbonyl group $(\mathrm{C}=\mathrm{O})$ of amide I at $1674 \mathrm{~cm}^{-1}$, nitrogen-hydrogen $(\mathrm{NH})$ stretch in amide II peptide bonds at $1481 \mathrm{~cm}^{-1}$ and amide III random stretching at $1251 \mathrm{~cm}^{-1}$ ) (Figure 6B). Conversely, all treatments resulted in decreased protein using the peak at $1432 \mathrm{~cm}^{-1}$ and carbohydrates (carboncarbon (C-C) skeletal or carbon-oxygen-hydrogen (C-O-H) deformations at $\left.1042 \mathrm{~cm}^{-1}\right)$.

Furthermore, a peak assignable to nucleic acids (oxygen-phosphate-oxygen (OPO) symmetrical stretching at $746 \mathrm{~cm}^{-1}$ ) was substantially reduced.

Diuron is a highly toxic phenylurea herbicide that acts by inhibiting electron transport chain in photosystem II $[23,46]$. Caernohabditis elegans exhibit age-specific sensitivity which does not compromise reproductive endpoints but life history traits like survival and longevity. The mode of action of diuron in C. elegans could be similar to plants, which depends on the 
generation of ROS that causes disruption of the mitochondrial electron transport chain with resulting effects on overall metabolism and energy budget. Additionally elevated ROS may also cause peroxidative destruction of pigments, nucleic acids, proteins and lipids [47]. Finally it is known that diuron can act as an androgen inhibitor through interacting with the aryl hydrocarbon receptor [46].

There was no significant effect of imidacloprid exposure on C. elegans reproduction, even at the highest tested concentration of $480 \mathrm{mg} / \mathrm{L}$. At the highest tested concentrations there was some indication of a possible small effect resulting from exposure. Any concentration response was, however, small, with the maximum effect size being a $22 \%$ reduction compared to controls at the highest tested concentration. This suggests that this treatment may correspond to an approximate $\mathrm{EC}_{20}$ and that the $\mathrm{EC}_{50}$ could be expect to be considerably higher. This assessment of the effect of $C$. elegans reproduction is consistent with the previous study of Gomez-Eyles et al. [23] who found both a shallow concentration response relationship and $\mathrm{EC}_{50}$ in excess of the highest tested concentration $(519 \mathrm{mg} / \mathrm{L})$ in a test conducted to assess neonicotinoid pesticide effects on nematodes in a agar based exposure. These results suggest that although imidacloprid may have a relatively high potency towards some invertebrate species including insects and annelids, this neonicotinoid shows a much lower potency for C. elegans.

The Raman phenotypes of C. elegans exposed to imidacloprid were similar compared to the control with no obvious concentration-dependent response seen for nematodes exposed to this compound with high overlap of control and exposed nematode spectra (Figure 7A). The reduction in polysaccharides (carbonyl group $(\mathrm{C}=\mathrm{O})$ vibration at $1044 \mathrm{~cm}^{-1}$ ) represented the largest change for any peak for all treatments (Figure 7B). There was also minor decrease in proteins (amino group $\left(\mathrm{NH}_{2}\right)$ deformations in amide II peptide linkage at $1585 \mathrm{~cm}^{-1}$ ) and protein 
and lipids (carbon-hydrogen $\left(\mathrm{CH}_{2}\right)$ deformation at $\left.1434 \mathrm{~cm}^{-1}\right)$. All concentrations consistently increased peaks assigned to proteins (carbonyl group $(\mathrm{C}=\mathrm{O})$ vibrations of amide $\mathrm{I}$ at $1672 \mathrm{~cm}^{-1}$,

nitrogen-hydrogen $(\mathrm{NH})$ deformation in amide II peptide bond at $1478 \mathrm{~cm}^{-1}$ and amide III random vibrations at $\left.1238 \mathrm{~cm}^{-1}\right)$ and lipids (carbon-hydrogen $\left(\mathrm{CH}_{2}\right)$ deformations at $\left.1478 \mathrm{~cm}^{-1}\right)$. Imidacloprid is an acetylcholine simulator that acts by inhibiting the nicotinic acetylcholine receptor without being sensitive to the action of acetyl cholinesterase which could result in over stimulation of cholinergic synapses [48]. Caenorhabditis elegans behaviours such as egg-laying, locomotion, feeding and mating are significantly compromised as they are linked directly or indirectly to cholinergic transmission [49]. Based on this mode of action the greater amount of imidacloprid could lead to paralysis of the nervous system that directly affects other cellular processes. Chronic exposure was found to up-regulate nicotinic acetylcholine receptor (AChR) without changing the sensitivity of the binding site [50]. However, although there is good reason to believe that the mechanisms of action through binding to the nicotinic acetylcholine receptors are likely to be relevant to effects in C. elegans, since previous work has I established the presence of member sub-unit proteins of this receptor in this species $[51,52]$. However if these is binding of imidacloprid to this receptor, this does not result in significant biochemical change that can be detected by Raman analysis.

\section{CONCLUSIONS}

The results of this study demonstrate the ability of Raman microspectroscopy to discriminate changes in cellular biochemical phenotypic in C. elegans exposed to inorganic and organic toxic stressors. Raman microspectroscopy provides a non-invasive and label-free method to detect these responses, coupled with PCA-LDA analysis to generate visualisation of treatment-induced effects. However, although it is possible to identify changes in Raman 
fingerprint in exposure to some chemicals, notably copper and diuron, this is not always the case. For example, in the exposure conducted with the neonicotinoid insecticide imidacloprid a change in Raman detected biochemical phenotypes was not observed In terms of relative sensitivity compared to a traditional life-cycle endpoint such as reproduction, there were two chemicals, copper and diuron, for which the Raman approach was able to identify changes in biochemical phenotype at concentrations. The effects seen on Raman detected biochemical phenotypes under copper exposure may be related to the fact that tested concentration elicited a greater toxic effect on reproduction that any other chemical. However, for diuron the 52\% knock-down observed was consistent with those for other chemicals (e.g. 50\% knock down by zinc at the three highest tested concentrations. Hence, it is unlikely that it is the magnitude of effect alone that is the cause of the effects on biochemical phenotypes observed for these two chemicals, especially as

effects were also seen at lower exposure concentrations for both chemicals.

In both cases effects on biochemistry were observed at concentrations an order of magnitude greater or lower than those causing a significant effect on reproduction. Both copper and diuron are known to have the potential to interact with the mitochondria, through direct interaction or excess ROS production. As the major cellular organelle responsible for endogenous metabolism, toxic effects on mitochondrial function may be expected to have major the potential to cause significant changes in biochemical phenotype. This may be in contrast to chemical with a non-metabolic mechanisms of action, such as the neurotoxin imidacloprid, for which more specific biochemical measurements of receptor interactions may be a better approach through which to identify biomarkers of low concentration exposure than whole organism biochemical analysis.

This article is protected by copyright. All rights reserved 
Raman spectroscopy can provide a broad fingerprint of an organisms' biomolecular composition, with peaks assignable to many of the major chemical components of the cell. As

we have shown, exposure to chemical stress can result in widespread changes in phenotype, including responses in chemical bonds associated with proteins, lipids, carbohydrates, and nucleic acids. Because of this, data provided by Raman spectroscopy has the potential to act as a hypothesis generator for further, more mechanistic studies on biochemical responses to stress. In addition, to further develop the application of Raman spectroscopy in ecotoxicology, there are a number of possible adaptation and refinements that could be made to optimise the use of this approach for biochemical based effect assessment. For example, in the present study, we chose to conduct data collection on a homogenous powder generated from whole nematodes. As a result, it is impossible to discriminate phenotypic changes that occur in limited cell types or regions of the nematodes. However, Raman microspectrometers are capable of micron-scale mapping, and this has previously been applied to generate spatially resolved chemical maps of nematodes [12]. Future work could use Raman mapping to identify tissues or cells in nematodes I that exhibit higher stress in response to chemical exposure. This ability to identify biochemical changes in specific tissue types could provide a means to identify those specific changes in metabolism phenotype that may be associated with particular mechanisms of action, including neurotoxicity, that are linked to effects of particular biochemical or biochemical pathways and target cell types or organs.

Supplemental Data - The Supplemental Data are available on the Wiley Online Library at DOI: 10.1002/etc.xxxx.

Acknowledgment-The authors than J. Trevisan for designing the computational framework used in this study.

This article is protected by copyright. All rights reserved 
Data availability - All data used in this study are available in the Supplemental Data.

\section{REFERENCES}

1. Borner J, Buchinger S, Schomburg D. 2007. A high-throughput method for microbial metabolome analysis using gas chromatography/mass spectrometry. Anal Biochem. 367:143-151.

Schirmer K, Fischer BB, Madureira DJ, Pillai S. 2010. Transcriptomics in ecotoxicology. Anal. Bioanal. Chem. 397:917-923.

3. Silvestre F, Gillardin V, Dorts J. 2012. Proteomics to assess the role of phenotypic plasticity in aquatic organisms exposed to pollution and global warming. Integr. Comp. Biol. 52, pp 681-694.

4. Biales AD, Kostich M, Burgess RM, Ho KT, Bencic DC, Flick RL, Portis LM, Pelletier MC, Perron MM, Reiss M. 2013. Linkage of genomic biomarkers to whole organism end points in a Toxicity Identification Evaluation (TIE). Environ. Sci. Technol. 47:1306-1312.

5. Snape JR, Maund SJ, Pickford DB, Hutchinson TH. 2004. Ecotoxicogenomics: The 1 challenge of integrating genomics into aquatic and terrestrial ecotoxicology. Aquat. Toxicol. 67:143-154.

Jarvis RM, Goodacre R. 2008. Characterisation and identification of bacteria using SERS. Chem. Soc. Rev. 37:931-936.

7. Kelly JG, Trevisan JJ, Scott AD, Carmichael PL, Pollock HM, Martin-Hirsch PL, Martin FL. 2011. Biospectroscopy to metabolically profile biomolecular structure: A multistage approach linking computational analysis with biomarkers. J. Proteome Res. 10:14371448.

This article is protected by copyright. All rights reserved 
8. Huang WE, Li M, Jarvis RM, Goodacre R, Banwart S a. 2010. Shining light on the microbial world the application of Raman microspectroscopy. Adv. Appl. Microbiol. 70, Elsevier Academic Press Inc, San Diego, pp 153-186.

9. Walter A, Reinicke M, Bocklitz T, Schumacher W, Rösch P, Kothe E, Popp J. 2011. Raman spectroscopic detection of physiology changes in plasmid-bearing Escherichia coli with and without antibiotic treatment. Anal. Bioanal. Chem. 400:2763-2773.

10. Read DS, Woodcock DJ, Strachan NJCC, Forbes KJ, Colles FM, Maiden MCJJ, CliftonHadley F, Ridley A, Vidal A, Rodgers J, Whiteley AS, Shepparde SK. 2013. Evidence for phenotypic plasticity among multihost Campylobacter jejuni and C. coli lineages, obtained using ribosomal multilocus sequence typing and raman spectroscopy. Appl. Environ. Microbiol. 79:965-973.

11. Mariani MM, Day PJR, Deckert V. 2010. Applications of modern micro-Raman spectroscopy for cell analyses. Integr. Biol. (Camb). 2:94-101.

12. Lau K, Hobro A, Smith T, Thurston T, Lendl B. 2012. Label-free non-destructive in situ 1) biochemical analysis of nematode Steinernema kraussei using FPA-FTIR and Raman spectroscopic imaging. Vib. Spectrosc. 60:34-42.

Krafft C. 2004. Bioanalytical applications of Raman spectroscopy. Anal. Bioanal. Chem. 378:60-62.

14. Chan J, Fore S, Wachsmann-Hogiu S, Huser T. 2008. Raman spectroscopy and microscopy of individual cells and cellular components. Laser Photonics Rev. 2:325-349.

15. Matousek P. 2007. Deep non-invasive Raman spectroscopy of living tissue and powders. Chem. Soc. Rev. 36:1292.

This article is protected by copyright. All rights reserved 
16. De Luca AC, Mazilu M, Riches A, Herrington CS, Dholakia K. 2010. Online fluorescence suppression in modulated raman spectroscopy. Anal. Chem. 82:738-745.

Bonnier F, Byrne HJ. 2012. Understanding the molecular information contained in principal component analysis of vibrational spectra of biological systems. Analyst. $137: 322$.

18. Das RS, Agrawal YK. 2011. Raman spectroscopy: Recent advancements, techniques and applications. Vib. Spectrosc. 57:163-176.

19. Walter A, Kuhri S, Reinicke M, Bocklitz T, Schumacher W, Rösch P, Merten D, Büchel G, Kothe E, Popp J. 2012. Raman spectroscopic detection of Nickel impact on single Streptomyces cells - Possible bioindicators for heavy metal contamination. J. Raman Spectrosc. 43:1058-1064.

20. Yu ZY, Chen XX, Zhang J, Wang R, Yin DQ. 2013. Transgenerational effects of heavy metals on L3 larva of Caenorhabditis elegans with greater behavior and growth inhibitions in the progeny. Ecotoxicol. Environ. Saf. 88:178-184.

2008. Nematode growth medium (NGM). Cold Spring Harb. Protoc. 2008:pdb.rec11474rec11474.

Tyne W, Lofts S, Spurgeon DJ, Jurkschat K, Svendsen C. 2013. A new medium for Caenorhabditis elegans toxicology and nanotoxicology studies designed to better reflect natural soil solution conditions. Environ. Toxicol. Chem. 32:1711-1717.

23. Gomez-Eyles JL, Svendsen C, Lister L, Martin H, Hodson ME, Spurgeon DJ. 2009. Measuring and modelling mixture toxicity of imidacloprid and thiacloprid on Caenorhabditis elegans and Eisenia fetida. Ecotoxicol. Environ. Saf. 72:71-79. 
24. Tyne W, Little S, Spurgeon DJ, Svendsen C. 2015. Hormesis depends upon the life-stage and duration of exposure: Examples for a pesticide and a nanomaterial. Ecotoxicol. Environ. Saf. 120:117-123.

25. Calafato S, Swain S, Hughes S, Kille P, Stürzenbaum SR, Sturzenbaum SR. 2008. Knock down of Caenorhabditis elegans cutc-1 Exacerbates the Sensitivity Toward High Levels of Copper. Toxicol. Sci. 106:384-391.

26. Konorov SO, Schulze HG, Caron NJ, Piret JM, Blades MW, Turner RFB. 2011. Raman microspectroscopic evidence that dry-fixing preserves the temporal pattern of non-specific differentiation in live human embryonic stem cells. J. Raman Spectrosc. 42:576-579. Trevisan J, Angelov PP, Scott AD, Carmichael PL, Martin FL. 2013. IRootLab: A free and open-source MATLAB toolbox for vibrational biospectroscopy data analysis.

Bioinformatics. 29:1095-1097.

28. Lau K, Hedegaard MAB, Kloepper JE, Paus R, Wood BR, Deckert V. 2011. Visualization and characterisation of defined hair follicle compartments by Fourier transform infrared (FTIR) imaging without labelling. J. Dermatol. Sci. 63:191-198.

Riding MJ, Trevisan J, Hirschmugl CJ, Jones KC, Semple KT, Martin FL. 2012. Mechanistic insights into nanotoxicity determined by synchrotron radiation-based Fouriertransform infrared imaging and multivariate analysis. Environ. Int. 50:56-65.

30. Martin FL, Kelly JG, Llabjani V, Martin-Hirsch PL, Patel II, Trevisan J, Fullwood NJ, Walsh MJ. 2010. Distinguishing cell types or populations based on the computational analysis of their infrared spectra. Nat. Protoc. 5:1748-1760.

This article is protected by copyright. All rights reserved 
31. Wang S, Wu L, Wang Y, Luo X, Lu Y. 2009. Copper-induced germline apoptosis in Caenorhabditis elegans: The independent roles of DNA damage response signaling and the dependent roles of MAPK cascades. Chem. Biol. Interact. 180:151-157.

32. Agarwal A, Gupta S, Sikka S. 2006. The role of free radicals and antioxidants in reproduction. Curr. Opin. Obstet. Gynecol. 18:325-332.

33. Bai H, Chen P, Tang GQ, Lin L, Fang H, Mu GG, Gong W, Liu ZP, Han ZB, Zhao H, Han ZC. 2011. Relations between reactive oxygen species and Raman spectral variations of Human Umbilical Cord Mesenchymal Stem cells with different viability. Laser Phys. 21.

Berlett BS, Stadtman ER. 1997. Protein oxidation in aging, disease, and oxidative stress. J. Biol. Chem. 272:20313-20316.

35. Dizdaroglu M, Jaruga P, Birincioglu M, Rodriguez H. 2002. Free radical-induced damage to DNA: Mechanisms and measurement. Free Radic. Biol. Med. 32:1102-1115.

36. Vijayakumar D, Suresh K, Manoharan S. 2006. Lipid peroxidation and antioxidant status 37. in blood of rheumatoid arthritis patients. Indian J. Clin. Biochem. 21:104-108. Harada H, Kurauchi M, Hayashi R, Eki T. 2007. Shortened lifespan of nematode Caenorhabditis elegans after prolonged exposure to heavy metals and detergents. Ecotoxicol. Environ. Saf. 66:378-383.

38. Boyd WA, Williams PL. 2003. Availability of metals to the nematode Caenorhabditis elegans : Toxicity based on total concentrations in soil and extracted fractions. Environ. Toxicol. Chem. 22:1100-1106.

39. Jager T, Zimmer EI. 2012. Simplified Dynamic Energy Budget model for analysing ecotoxicity data. Ecol. Modell. 225:74-81.

This article is protected by copyright. All rights reserved 
40. Swain S, Wren JF, Stürzenbaum SR, Kille P, Morgan a J, Jager T, Jonker MJ, Hankard PK, Svendsen C, Owen J, Hedley BA, Blaxter M, Spurgeon DJ. 2010. Linking toxicant physiological mode of action with induced gene expression changes in Caenorhabditis elegans. BMC Syst. Biol. 4:32.

41. Migliore L, Coppedè F. 2009. Environmental-induced oxidative stress in neurodegenerative disorders and aging. Mutat. Res. - Genet. Toxicol. Environ. Mutagen. 674:73-84.

42. Wang D, Shen L, Wang Y. 2007. The phenotypic and behavioral defects can be transferred from zinc-exposed nematodes to their progeny. Environ. Toxicol. Pharmacol. $24: 223-230$.

43. Roh HC, Collier S, Deshmukh K, Guthrie J, Robertson JD, Kornfeld K. 2013. ttm-1

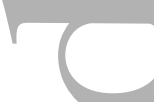
Encodes CDF Transporters That Excrete Zinc from Intestinal Cells of C. elegans and Act in a Parallel Negative Feedback Circuit That Promotes Homeostasis. In Eide, DJ, ed., PLoS Genet. 9:e1003522.

Hooper HL, Jurkschat K, Morgan AJ, Bailey J, Lawlor AJ, Spurgeon DJ, Svendsen C. 2011. Comparative chronic toxicity of nanoparticulate and ionic zinc to the earthworm Eisenia veneta in a soil matrix. Environ. Int. 37:1111-1117.

45. Wang DY, Yang P. 2007. Silver exposure causes transferable defects of phenotypes and behaviors in nematode Caenorhabditis elegans. Environ. Bioindic. 2:89-98.

46. McKinlay R, Plant JA a., Bell JNBNB, Voulvoulis N. 2008. Endocrine disrupting pesticides: Implications for risk assessment. Environ. Int. 34:168-183.

This article is protected by copyright. All rights reserved 
47. Ihlaseh SM, Bailey KA, Hester SD, Jones C, Ren H, Cardoso APF, Oliveira MLCS, Wolf DC, de Camargo JL V. 2011. Transcriptional profile of diuron-induced toxicity on the urinary bladder of male wistar rats to inform mode of action. Toxicol. Sci. 122:330-338.

48. Key P, Chung K, Siewicki T, Fulton M. 2007. Toxicity of three pesticides individually and in mixture to larval grass shrimp (Palaemonetes pugio). Ecotoxicol. Environ. Saf. $68: 272-277$

49. Leelaja BC, Rajini PS. 2013. Biochemical and physiological responses in Caenorhabditis elegans exposed to sublethal concentrations of the organophosphorus insecticide, monocrotophos. Ecotoxicol. Environ. Saf. 94:8-13.

50. Tomizawa M, Casida JE. 2005. Neonicotinoid insecticide toxicology: mechanisms of selective sction. Annu. Rev. Pharmacol. Toxicol. 45:247-268.

51. Ballivet M, Alliod C, Bertrand S, Bertrand D. 1996. Nicotinic acetylcholine receptors in the nematode Caenorhabditis elegans. J Mol Biol. 258:261-269.

52. Holden-Dye L, Joyner M, O'Connor V, Walker RJ. 2013. Nicotinic acetylcholine 1 Ieceptors: A comparison of the nAChRs of Caenorhabditis elegans and parasitic nematodes. Parasitol. Int. 62:606-615.

This article is protected by copyright. All rights reserved 
Figure 1. Responses of reproduction as total offspring rate over $72 \mathrm{~h}$ to exposure to the a range of concentrations of (A) copper, (B) zinc, (C) silver, (D) diuron, (E) imidacloprid.

Figure 2. The projected computational results and analysis for copper (II) chloride (A) Onedimensional PCA-LDA scatter plot indicating the segregation of scores following nematode exposure $(\mathrm{mg} / \mathrm{L})$ to copper chloride. The enlarged symbol in middle indicates the mean score value. (B) Copper chloride cluster vectors plot showing significant peaks that increased after exposure. In all cluster vectors plots, the control is set as the origin.

Figure 3. The projected computational results and analysis for zinc chloride (A) Onedimensional PCA-LDA scatter plot indicating the segregation of scores following nematode exposure to zinc chloride. The enlarged symbols in the middle of each plot represent the mean value. (B) Zinc chloride cluster vectors plot showing significant peaks that increased in intensity after exposure. In all cluster vectors plots, the control is set as the origin.

Figure 4. The projected computational results and analysis for silver nitrate (A) One-dimensional PCA-LDA scatter plot indicating the segregation of scores following nematode exposure (mg $/ \mathrm{L}$ ) to silver nitrate. The enlarged symbols in the middle of each plot represent the mean value. (B)

Silver nitrate cluster vectors showing significant peaks that increased after exposure. In all cluster vectors plots, the control is set as the origin.

Figure 5. The projected computational results and analysis for acetone carrier (A) One dimensional PCA-LDA scatter plot of carrier compared to the baseline control to examine the effects of acetone on nematode spectral phenotypes. The enlarged symbols in the middle of each plot represent the mean value. (B) Carrier cluster vectors plot showing the most significant wavenumbers, control was set as origin.

This article is protected by copyright. All rights reserved 
Figure 6. The projected computational results and analysis for diuron (A) One-dimensional PCA-LDA scatter plot for Diuron. The enlarged symbols in the middle of each plot represent the mean value. The enlarged symbols in the middle of each plot represent the mean value. (B) Diuron cluster vectors showing significant peaks that increased after exposure. In all cluster vectors plots, the control is set as the origin.

1

Figure 7. The projected computational results and analysis for imidacloprid (A) One-dimensional PCA-LDA scatter plot for imidacloprid. The enlarged symbols in the middle of each plot represent the mean value. In all cluster vectors plots, the control is set as the origin. (B) Imidacloprid cluster vectors plot showing significant peaks that increased after exposure.

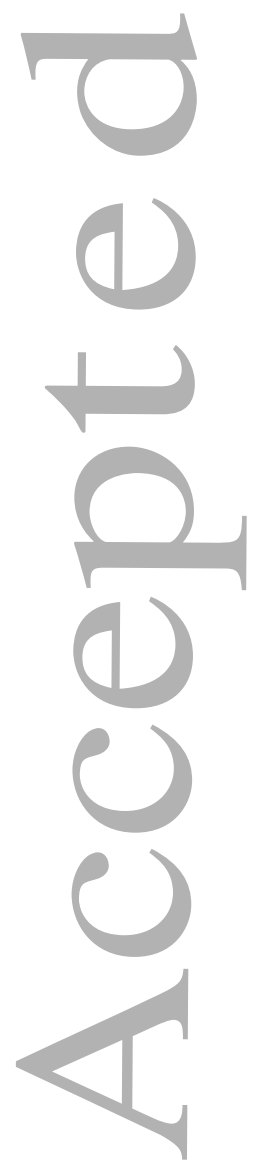

This article is protected by copyright. All rights reserved 
Table 1 Prepared molar concentrations of stock solutions and the volume (ml) of each stock added to 1 litre of distilled water to prepare synthetic soil pore water (SSPW).

\begin{tabular}{|l|l|l|}
\hline Component & Stock concentration (M) & Volume (ml) / L SSPW \\
\hline $\mathrm{NaHCO}_{3}$ & 0.1 & 40 \\
\hline $\mathrm{Ca}\left(\mathrm{NO}_{3}\right)_{2}$ & 0.1 & 10 \\
\hline $\mathrm{MgSO}_{4}$ & \multicolumn{1}{|c|}{0.1} & 12.5 \\
\hline $\mathrm{Na}_{2} \mathrm{HPO}_{4}$ & 0.1 & 5 \\
\hline $\mathrm{HNO}_{3}$ & 0.1 & 0.01 \\
\hline Iron standard & $0.0179(1 \mathrm{~g} / \mathrm{l})$ & 10 \\
\hline Aluminium standard & $0.037(1 \mathrm{~g} / \mathrm{l})$ & 0.559 \\
\hline
\end{tabular}

This article is protected by copyright. All rights reserved 
Table 2 Summary of the averaged PCA-LDA loadings showing the six significant wavenumbers $\left(\mathrm{cm}^{-1}\right)$ induced consistently by the different treatments concentration.

\begin{tabular}{|l|l|l|l|l|l|l|}
\hline Ranked order & & & & & \\
\hline of contributing & Copper & Copper & Silver & Zinc & & \\
\hline Raman peaks & chloride & sulphate & nitrate & chloride & Diuron & Imidacloprid \\
\hline 2 & 754 & 783 & 783 & 783 & 781 & 746 \\
\hline 3 & 991 & 995 & 1080 & 1044 & 991 & 1124 \\
\hline 4 & 1049 & 1051 & 1331 & 1090 & 1042 & 1249 \\
\hline 5 & 1460 & 1223 & 1434 & 1481 & 1223 & 1479 \\
\hline 6 & 1663 & 1467 & 1481 & 1691 & 1479 & 1583 \\
\hline
\end{tabular}

This article is protected by copyright. All rights reserved 


\section{Figure 1}
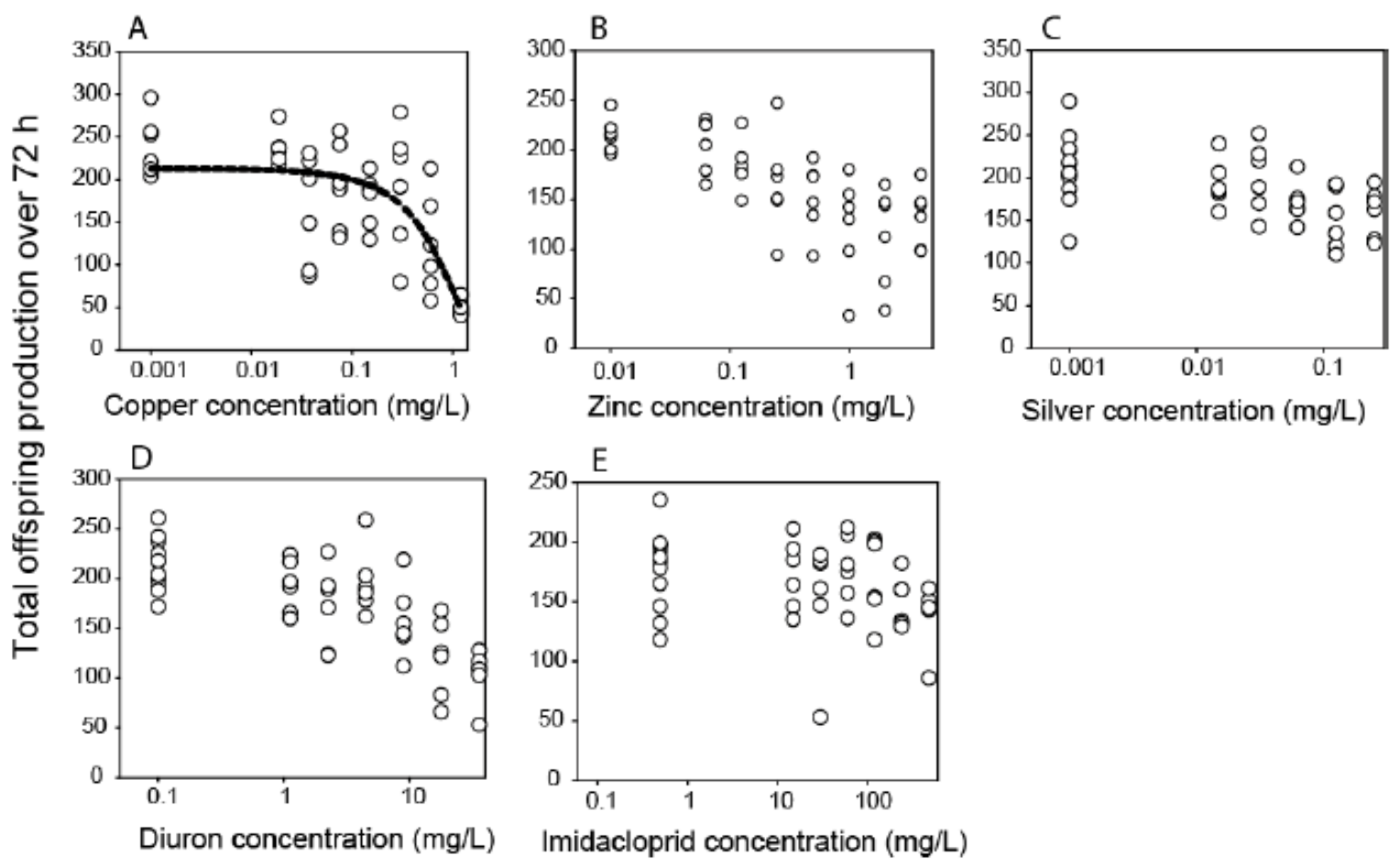

This article is protected by copyright. All rights reserved 
Figure 2

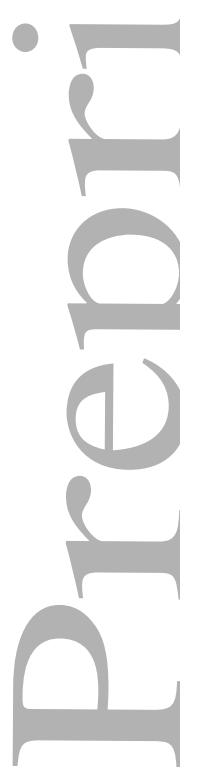

A) Copper (II) chloride 1-D Scatter Plot

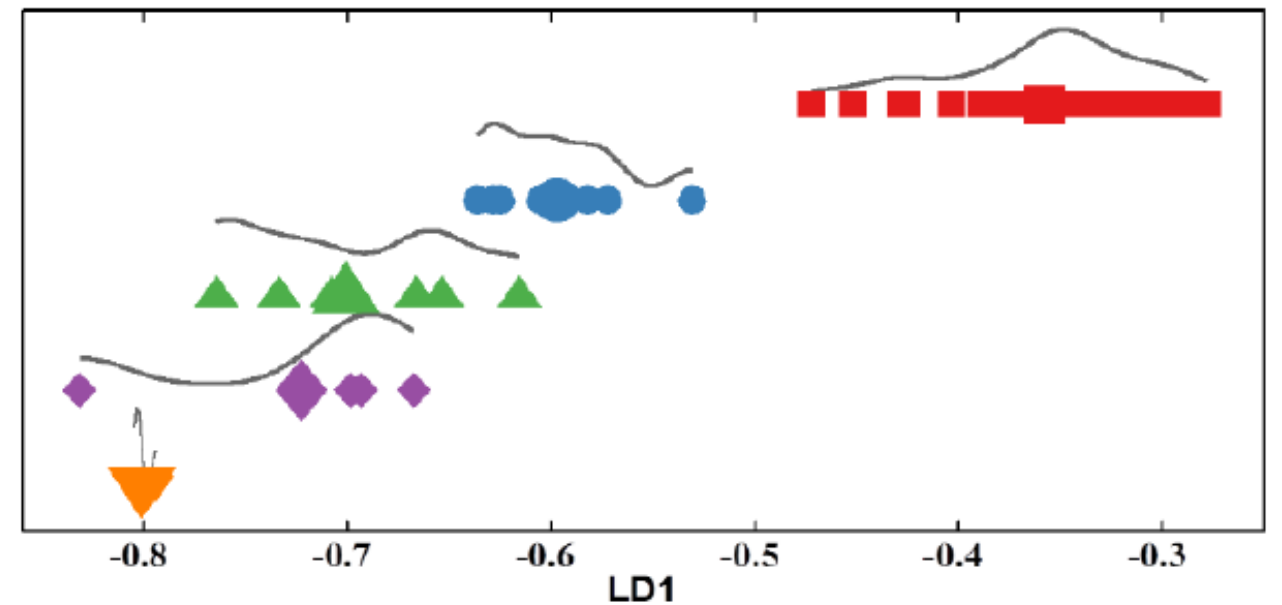

B) Copper (II) chloride cluster vector plot

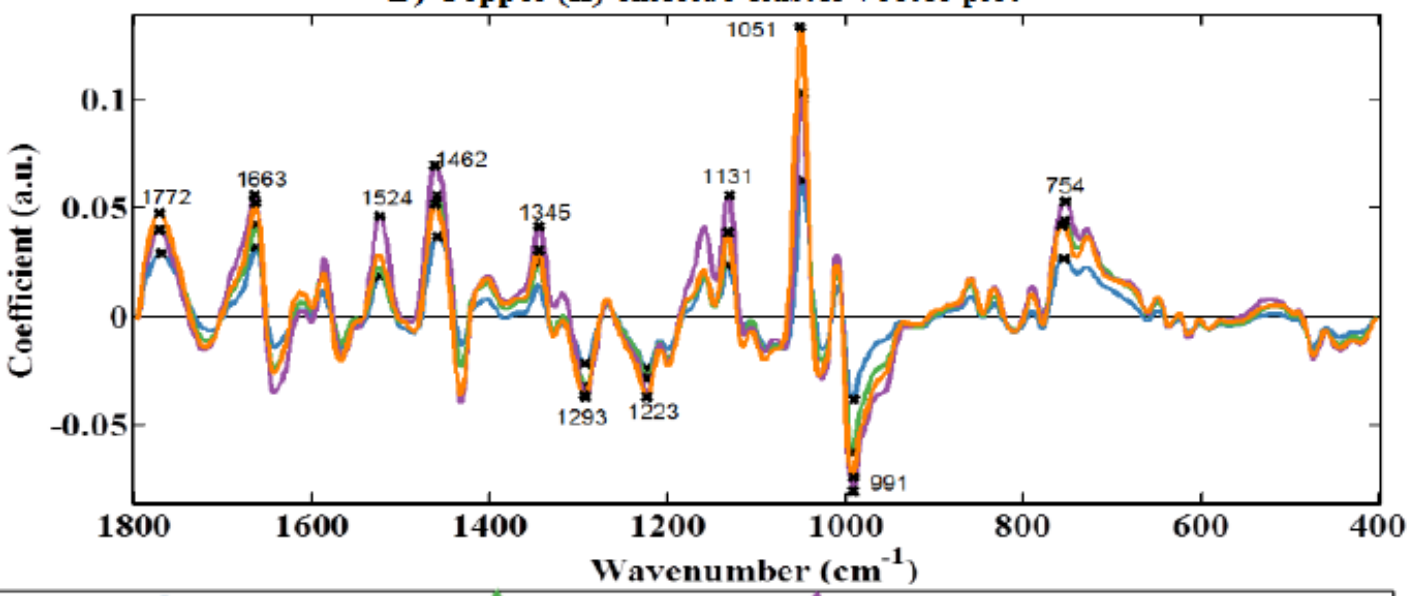

Control $O$ Copper chloride $(0.01875) \triangle$ Copper chloride $(0.0375)>$ Copper chloride $(0.075) \nabla$ Copper chloride $(0.15)$

This article is protected by copyright. All rights reserved 


\section{Figure 3}

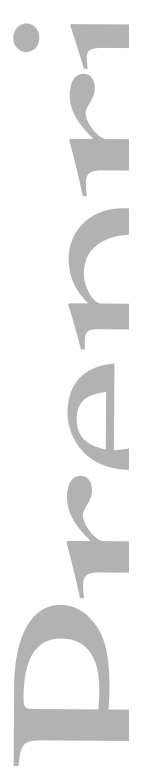

A) Zinc chloride 1-D Scatter Plot

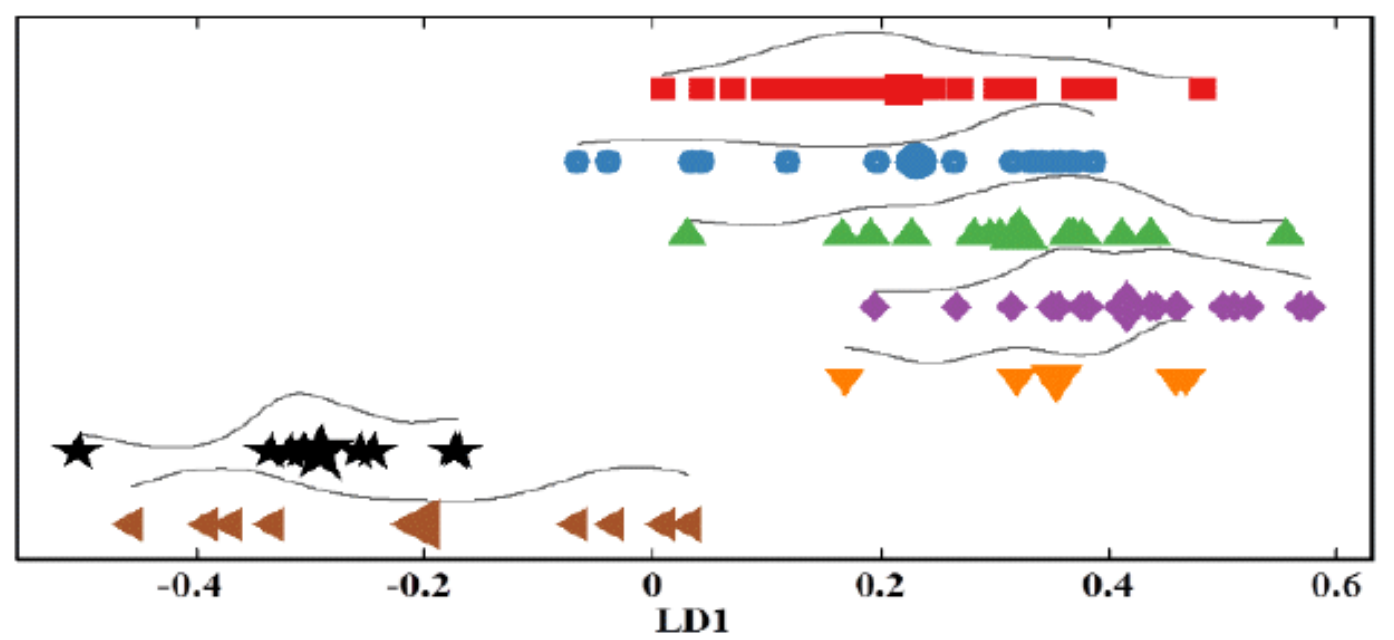

B) Zinc cluster vector plot

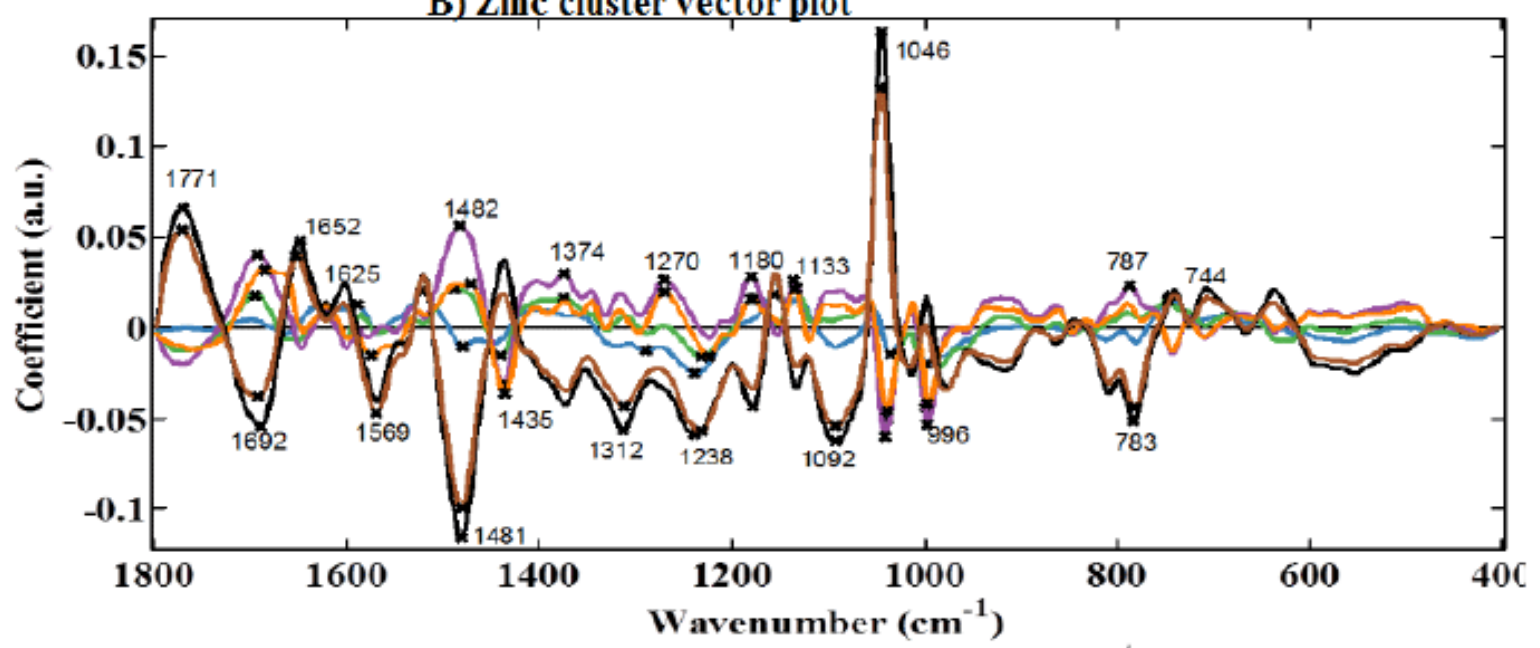

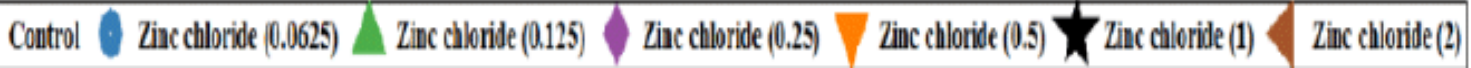

This article is protected by copyright. All rights reserved 


\section{Figure 4}

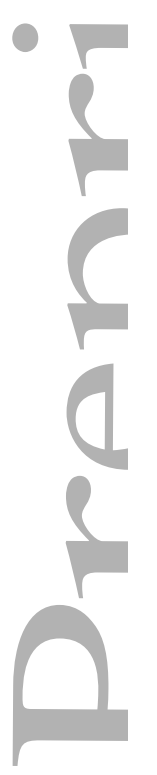

A) Silver nitrate 1-D Scatter Plot

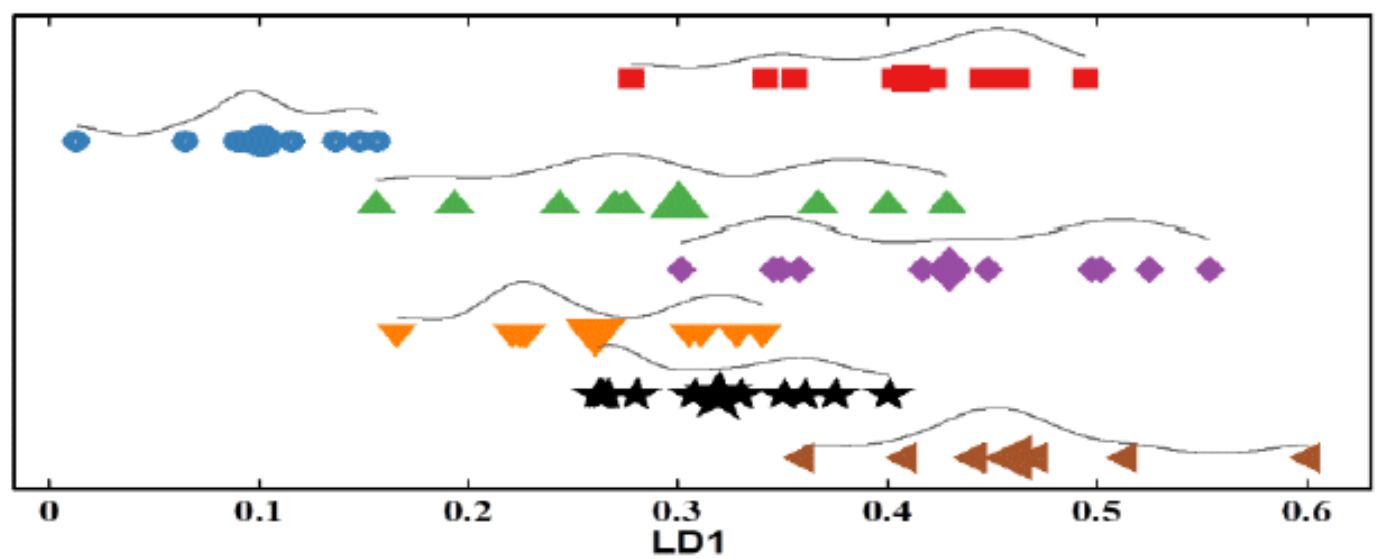

B) Silver nitrate cluster vector plot

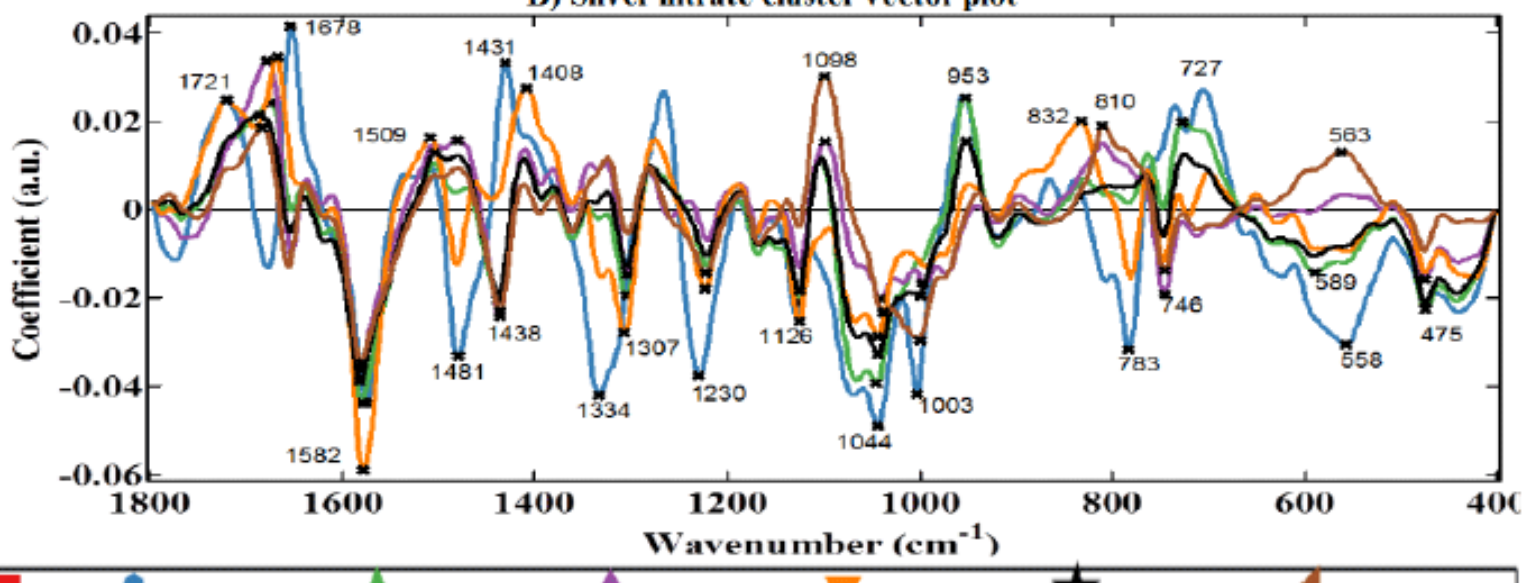

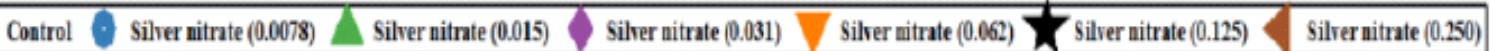

This article is protected by copyright. All rights reserved 


\section{Figure 5}
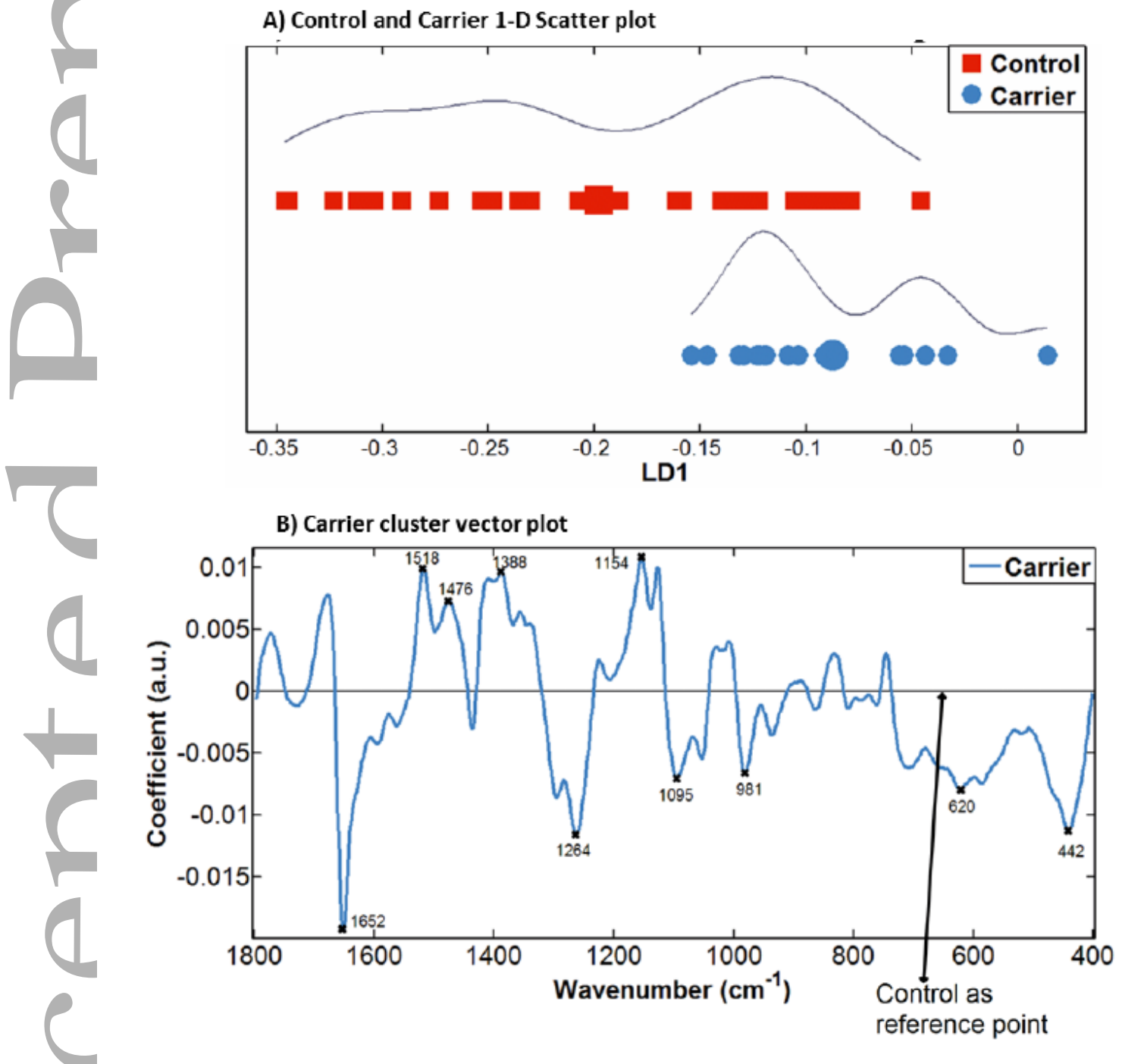

This article is protected by copyright. All rights reserved 
Figure 6

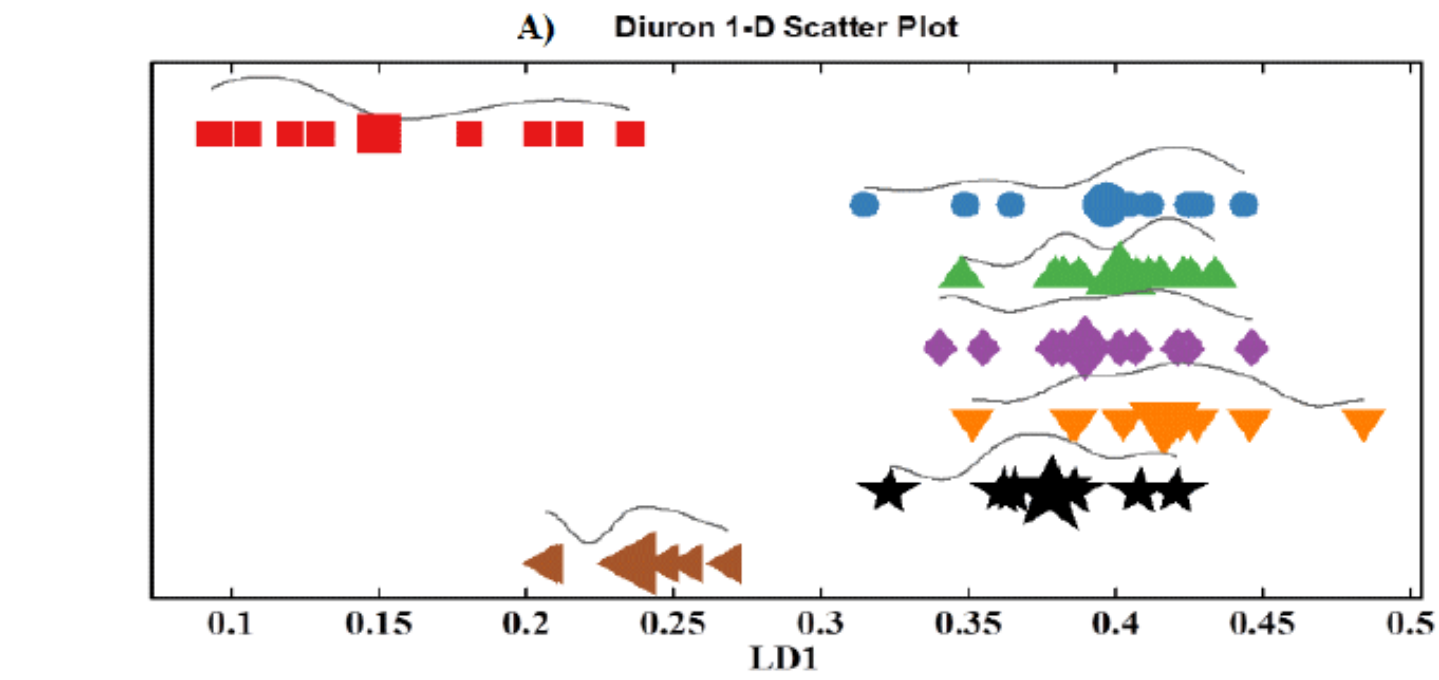

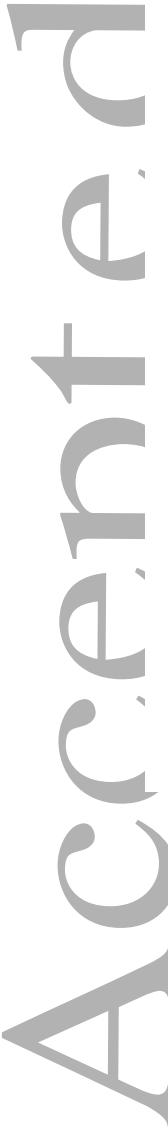

B) Diuron cluster vector plot

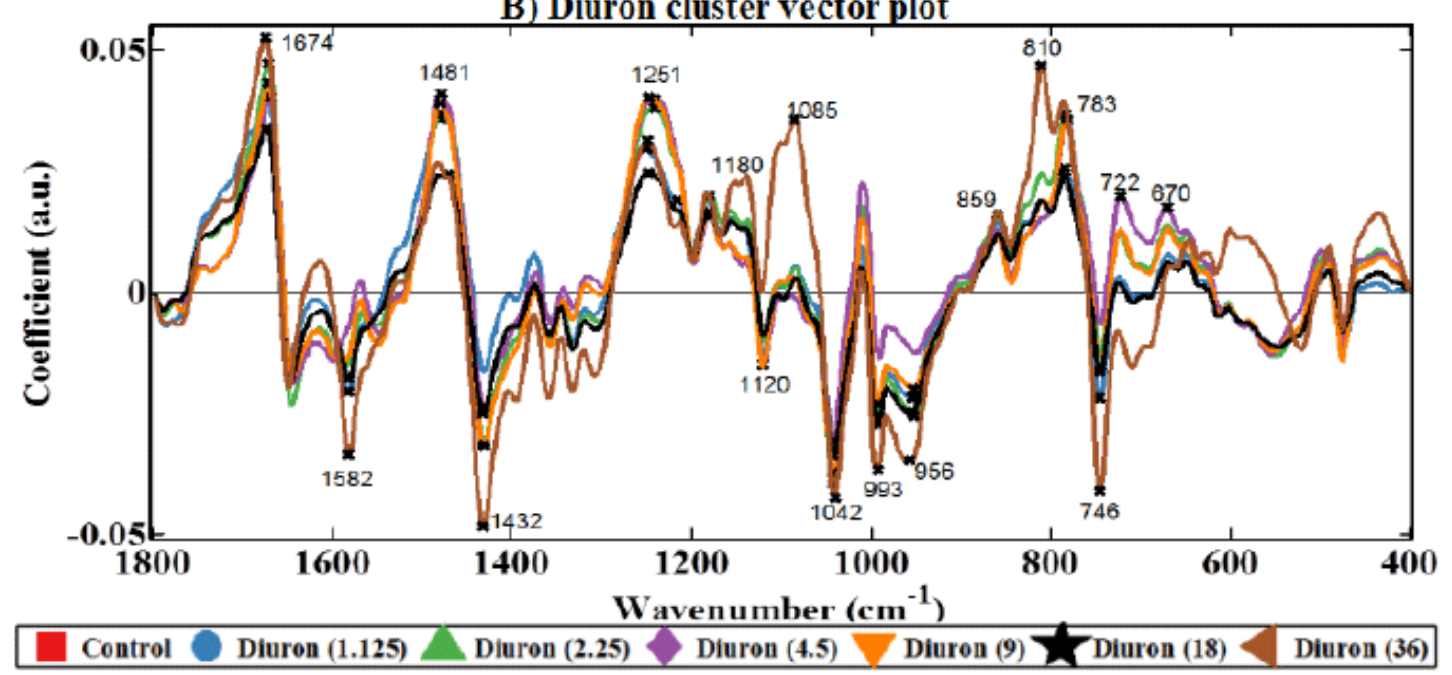

This article is protected by copyright. All rights reserved 
Figure 7
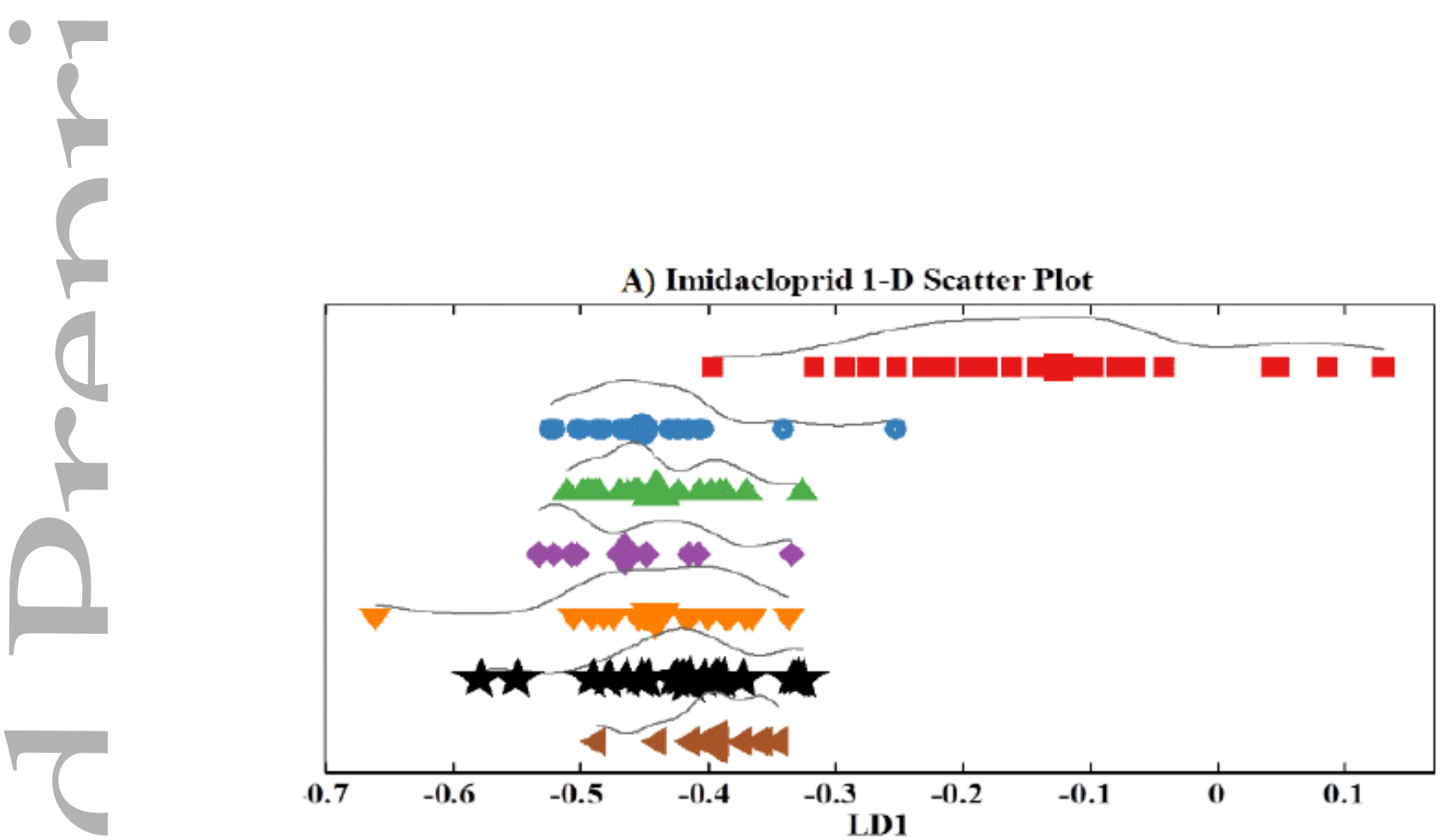

B) Imidacloprid cluster vector plot

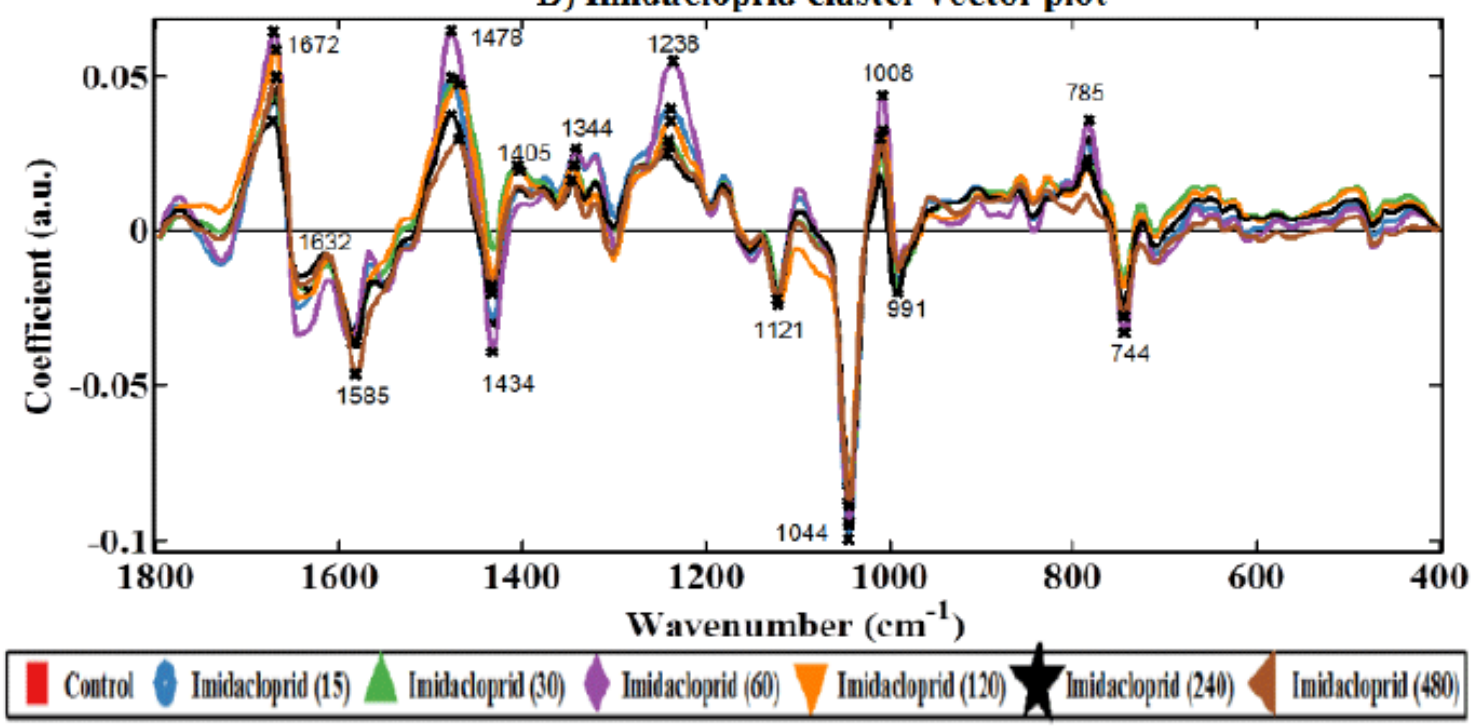

This article is protected by copyright. All rights reserved 